\title{
Solid Solubility Metastable Extension of Some Transition Metals in Gold
}

\author{
Li Qubo and Zhou Xinming \\ Institute of Precious Metals, Kunming, Yunnan, 650221, China
}

\begin{abstract}
The metastable extended solid solubilities of the transition metals $\mathrm{Ti}, \mathrm{Zr}, \mathrm{Hf}, \mathrm{W}, \mathrm{Re}, \mathrm{Ru}$ and $\mathrm{Rh}$ in gold have been studied by measuring the lattice parameters of their gold-rich solid solutions using X-ray diffraction. The cooling rate used for the preparation of the alloys was about $10^{6} \mathrm{~K} / \mathrm{s}$. It was found that the metastable solid solubilities of $\mathrm{Ti}, \mathrm{Zr}$ and $\mathrm{Hf}$ in gold were 18.2, 13.0, and 13.4 at $\%$ respectively, but that those of W, Re, $\mathrm{Ru}$, and $\mathrm{Rh}$ in gold were negligible. It is concluded that metastable extension of the solid solubilities of transition metals in gold is relative to the nature of the phase diagrams of their alloys with gold. Under conditions of rapid solidification, the alloys with upper-peritectic-type phase diagrams had significant solid solubility extensions and the alloys with monotectic-type phase diagrams displayed little solid solubility extension. Mechanical alloying may be more effective in producing metastable solid solutions of these alloys.
\end{abstract}

In a preceding article (1), the authors reported upon studies of the metastable extension of the solid solubilities of rare earth (RE) metals in gold. It was found that the metastable solid solubilities of $\mathrm{Ce}, \mathrm{Sm}$, $\mathrm{Gd}, \mathrm{Dy}, \mathrm{Er}, \mathrm{Yb}$, and $\mathrm{Y}$ in gold were $0.3,0.4,1.5,9.0$, $13,13.4$, and 10 at $\%$ respectively, and that the solid solubilities of rare earth metals in gold increased with decreasing relative difference of atomic radius between the RE metal and gold. From a comparison of the extended solid solubilities of rare earth metals in gold, silver, and copper, it was concluded that the relatively large solid solubility in gold could be explained in terms of electron transfer from the RE atoms to gold atoms. Under the conditions of rapid solidification, the $\mathrm{Au}-\mathrm{RE}$ alloys tended to form amorphous alloys more readily than did the Ag-RE alloys.

In this paper, the metastable extension of solid solubility of transition metals $\mathrm{M}(\mathrm{M}=\mathrm{Ti}, \mathrm{Zr}, \mathrm{Hf}, \mathrm{W}$, $\mathrm{Re}, \mathrm{Ru}, \mathrm{Rh}$ ) in gold by rapid solidification is described.

\section{EXPERIMENTAL}

The alloys used were prepared from high (99.999\%) purity gold and pure $(99.9 \%)$ transition metals ( $\mathrm{Ti}, \mathrm{Zr}$, Hf, W, Re, Ru, Rh), by melting together of their components using a high frequency induction current.
A small piece of alloy was re-melted and made into thin foil of thickness $0.03-0.05 \mathrm{~mm}$ using an arcmelting hammer-anvil installation. The cooling rate for the rapid solidification was of the order of $10^{6} \mathrm{~K} / \mathrm{s}$.

The metastable extension of solid solubility in gold was determined by measuring the lattice parameters of gold-rich solid solutions of the rapidly solidified alloys. The same procedures are more fully described in our previous paper (1).

\section{RESULTS AND DISCUSSION}

The dependence of the lattice parameters of the gold-rich solid solutions on their transition metal concentrations in rapidly solidified alloys $(\mathrm{M}=\mathrm{Ti}, \mathrm{Zr}, \mathrm{Hf})$ is shown in Figure 1. Under rapid solidification conditions, the extended solid solubilities of $\mathrm{Ti}, \mathrm{Zr}$, and $\mathrm{Hf}$ in gold were $18.2,13.0$, and 13.4 at $\%$ respectively. In contrast, the lattice parameters of gold-rich solid solutions did not change significantly with the increasing of the transition metal concentration in $\mathrm{Au}-\mathrm{W}, \mathrm{Au}-\mathrm{Re}, \mathrm{Au}-\mathrm{Ru}$, and $\mathrm{Au}-$ $\mathrm{Rh}$ alloys. The results indicated that the extension of solid solubilities of $\mathrm{W}, \mathrm{Re}, \mathrm{Ru}$, or $\mathrm{Rh}$ in gold by rapid solidification were negligible, and it was therefore difficult to precisely determine the extended solid solubility by measuring the lattice parameters. 


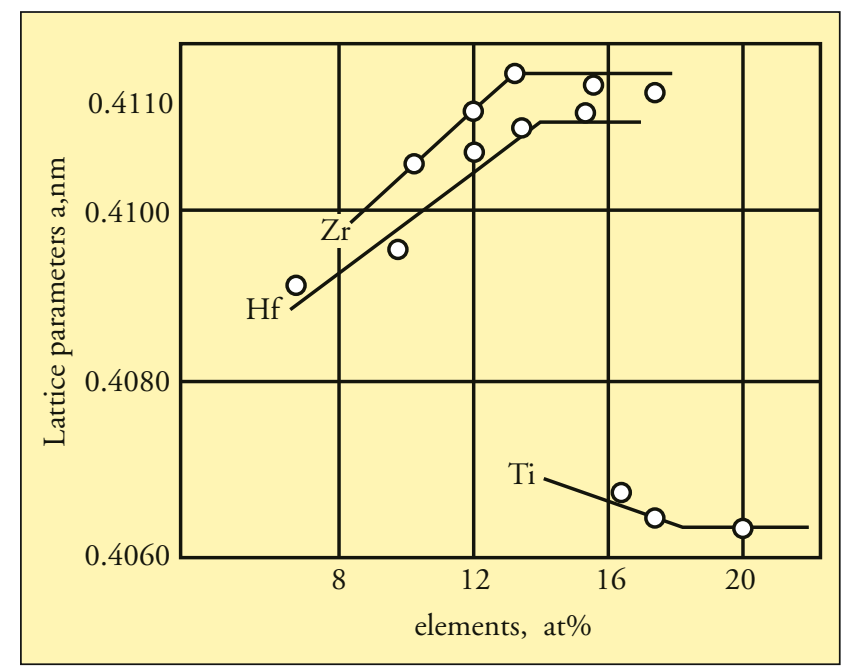

Figure 1 Lattice parameters of Au-rich solid solutions vs composition of rapidly solidified $A u-T i, A u-Z r$, and Au-Hfalloys

The metastable extension of the solid solubilities of the transition metals $\mathrm{Ti}, \mathrm{Zr}, \mathrm{Hf}, \mathrm{W}, \mathrm{Re}, \mathrm{Ru}$, and $\mathrm{Rh}$ in gold could be related to the binary phase diagram characteristics of the respective alloys. The parameters and phase diagram characteristics of gold and the transition metals used here are listed in Table 1.

The results of X-ray diffraction measurements indicated that intermetallic compounds $\mathrm{Au}_{4} \mathrm{M}(\mathrm{M}=$ $\mathrm{Ti}, \mathrm{Zr}$, Hf) appeared when alloy composition went beyond the metastable solid solubility in $\mathrm{Au}-\mathrm{Ti}, \mathrm{Au}-\mathrm{Zr}$, and Au-Hf alloys. In the equilibrium state, the first gold-rich compound implied by the phase diagram for the Au-Hf alloys is $\mathrm{Au}_{5} \mathrm{Hf}$, but under the rapid solidification conditions the formation of the $\mathrm{Au}_{4} \mathrm{Hf}$ compound became more favoured, and growth of the $\mathrm{Au}_{5} \mathrm{Hf}$ compound was restrained.
The atomic radius of $\mathrm{Ti}(0.1448 \mathrm{~nm})$ is slightly larger than that of $\mathrm{Au}(0.1442 \mathrm{~nm})$ (3). Under normal conditions the lattice parameter of the gold-rich solid solution should therefore increase when titanium is alloyed with it; but our measurements indicated that the addition of titanium to gold decreased the lattice parameter of the gold-rich solid solution. This may be related to electron transfer between the solute and solvent atoms when $\mathrm{Ti}$ is alloyed with gold. The same results were obtained during studies on the $\mathrm{Au}-\mathrm{Ti}$ equilibrium phase diagram (4).

The phase diagrams for $\mathrm{Au}-\mathrm{Ti}, \mathrm{Au}-\mathrm{Hf}$ and $\mathrm{Au}-\mathrm{Zr}$ are of the peritectic type. The melting points of the gold-rich solid solutions increased as the solute concentration increased. This type of phase diagram is called 'upper-peritectic'. We have previously pointed out (5) that the alloys with upper peritectic phase diagrams could display significant metastable extension of solid solubility on rapid solidification. The Au-W and Au-Re alloys have simple eutectic type phase diagrams. The eutectic temperatures are very close to the melting point of gold, and the eutectic compositions approach pure gold. For example the eutectic composition for the $\mathrm{Au}-\mathrm{W}$ alloy contains $0.137 \mathrm{at} \% \mathrm{~W}$. The Au-Ru and Au-Rh alloy systems have monotectic types of phase diagrams. The differences in the melting points between the solute metals and the gold solvent are very large, and no intermetallic compounds form. This indicates that the mixing enthalpy for gold with these transition metals is large and positive and that there is a strongly exclusive effect between the solvent and solute atoms, which is unfavourable to the formation of solid solutions. Extension of the solid solubility is therefore scarcely to be expected under rapid solidification conditions. The technique of mechanical alloying may be more

Table 1 The parameters and phase diagram characteristics of gold and transition metals (references 2 and 3).

\begin{tabular}{|c|c|c|c|c|c|c|c|c|}
\hline & Au & Ti & $\mathbf{Z r}$ & Hf & $\mathbf{W}$ & $\mathbf{R e}$ & $\mathbf{R u}$ & $\mathbf{R h}$ \\
\hline Atomic radius, nm & 0.1442 & 0.1448 & 0.1590 & 0.1564 & 0.1371 & 0.1371 & 0.1325 & 0.1345 \\
\hline Crystal structure & f.c.c. & $\begin{array}{l}\text { f.c.c. } \\
\text { h.c.p. }\end{array}$ & $\begin{array}{l}\text { f.c.c. } \\
\text { h.c.p. }\end{array}$ & $\begin{array}{l}\text { f.c.c. } \\
\text { h.c.p. }\end{array}$ & b.c.c & h.c.p. & h.c.p. & f.c.c. \\
\hline Melting-point & 1064.43 & 1670 & 1855 & 2231 & 3422 & 3186 & 2334 & 1963 \\
\hline $\begin{array}{l}\text { Type of phase diagram } \\
\text { between Au and elements }\end{array}$ & - & $\begin{array}{l}\text { peri- } \\
\text { tectic }\end{array}$ & $\begin{array}{l}\text { peri- } \\
\text { tectic }\end{array}$ & $\begin{array}{l}\text { peri- } \\
\text { tectic }\end{array}$ & eutectic & eutectic & $\begin{array}{l}\text { mono- } \\
\text { tectic }\end{array}$ & $\begin{array}{l}\text { mono- } \\
\text { tectic }\end{array}$ \\
\hline First gold-rich compound & - & $\mathrm{TiAu}_{4}$ & $\mathrm{ZrAu}_{4}$ & $\mathrm{HfAu}_{5}$ & - & - & - & - \\
\hline $\begin{array}{l}\text { Peritectic, eutectic } \\
\text { or monotectic temperature, }{ }^{\circ} \mathrm{C}\end{array}$ & - & 1123 & 1065 & $\sim 1064$ & 1063 & - & 2012 & 1885 \\
\hline Equilibrium solid solubility, at\% & - & 12 & 7.25 & $5-10$ & - & $\approx 0.1$ & - & - \\
\hline Extended solid solubility, at\% & - & 18.2 & 13 & 13.4 & - & - & - & - \\
\hline
\end{tabular}


effective in producing metastable solid solutions of these alloys. Deng et al (6) used this method to obtain silver-rich Ag-W metastable solid solutions. Silver and tungsten are immiscible in both the solid and liquid states.

\section{CONCLUSIONS}

Under rapid solidification conditions, with a cooling rate of $10^{6} \mathrm{~K} / \mathrm{s}$, the metastable extended solid solubilities of $\mathrm{Ti}, \mathrm{Zr}$, and $\mathrm{Hf}$ in gold were 18.2, 13.0 and 13.4 at\% respectively. The metastable extended solid solubilities of W, Re, Ru, and Rh in gold were negligible.

There is a relationship between the metastable extended solid solubility behaviour and the characteristics of the phase diagrams of gold and the transition metals. The phase diagrams of $\mathrm{Au}-\mathrm{Ti}, \mathrm{Au}-\mathrm{Zr}$, and Au-Hf alloy systems are upper-peritectic in character and the solid solutions of these alloys can obviously be extended by rapid solidification. The phase diagrams of $\mathrm{Au}-\mathrm{W}, \mathrm{Au}-\mathrm{Re}, \mathrm{Au}-\mathrm{Ru}$, and $\mathrm{Au}-\mathrm{Rh}$ alloy systems are simple eutectic or monotectic in character, and the mixing enthalpy of their constituents is very large and positive, and the formation of solid solutions of these alloys is therefore restricted even under conditions of rapid solidification. The use of mechanical alloying procedures may be more favourable for obtaining metastable solid solutions of these alloys.

\section{ACKNOWLEDGEMENTS}

The authors wish to express their thanks to Senior Engineer Wang Zhongming for assistance with the Xray diffraction measurements.

\section{ABOUT THE AUTHORS}

Professor Zhou Xinming is currently a Research Fellow in the Institute of Precious Metals, Kunming, Yunnan, China. He has made many original contributions in the field of precious metals alloy materials, including high purity gold alloys for the electronics industry. He has also carried out substantial research on metastable alloys.

Li Qubo is a Senior Engineer and a member of Professor Zhou's research group. His recent research has been concerned with gold and gold alloys, including their use in the microelectronics industry.

\section{REFERENCES}

1 Z. Xinming and L. Qubo, Gold Bull., 1997, 30, 63

2 T.B. Massalski, 'Binary Alloy Phase Diagrams', American Society for Metals, Metals Park, Ohio, 1987

3 W.B. Pearson, 'The Crystal Chemistry and Physics of Metals and Alloys', John Wiley and Sons, Inc, New York, 1972

4 P. Pietroknowsky, J. Inst. Metals, 1961 - 62, 90, 434

5 N.Yuantao and Z. Xinming, J. Alloys and Compounds, 1992, 182, 131

6 D. Deng and Y. Xu, Precious Metals, 1993, 14, 22 (in Chinese) 